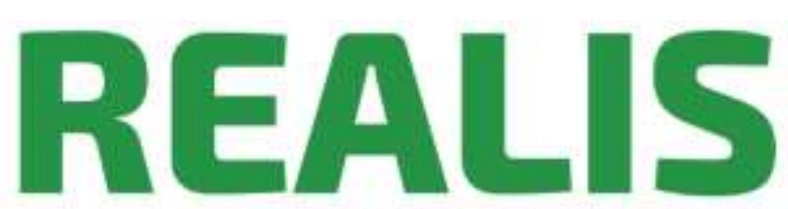

Revista de Estudos

AntiUtilitaristas e PosColoniais

\title{
O PROTAGONISMO DA CHINA NO NOVO BANCO DE DESENVOLVIMENTO (NBD) DOS BRICS E POSSÍVEIS CONTRADIÇÕES SOB A PRESIDÊNCIA BRASILEIRA ${ }^{1}$
}

The protagonism of china in the BRICS's new development bank (NDB) and possible contradictions under the brazilian presidency

BORGES, Fábio²

NAGUAL, Felipe ${ }^{3}$

MARTINS, Luiza Maria4

\begin{abstract}
Resumo: O Novo Banco de Desenvolvimento (NBD) é um banco que busca financiar projetos de infraestrutura e desenvolvimento sustentável nos BRICS (Brasil, Rússia, Índia, China e África do Sul), e em outras economias emergentes. Constituído em 2014, iniciou suas operações em 2016. A escolha da sede Xangai e a indicação de Chen Yuan, ex-presidente do Banco de Desenvolvimento Chinês, para liderar o país na construção do desenho do NBD, são indicadores relevantes da importância que os chineses conferem ao banco. Coube ao Brasil indicar o presidente do NBD em 2020: Marcos Troyjo. Mas as relações entre e Brasil e China se deterioraram no período Bolsonaro e com a explosão da Covid em 2020, os desentendimentos entre os países atingiram patamares inéditos. Esse artigo buscará identificar o protagonismo da China no NBD e apontar contradições de o Brasil estar exercendo a presidência do banco em um contexto de protagonismo mundial chinês.
\end{abstract}

Palavras-Chave: China; Protagonismo; NBD; Brasil, Contradições

\footnotetext{
1 Enviado em: 23 Out 2021. | Aceito em: 10 Nov 2021.

2 Professor na Universidade Federal da Integração Latino-americana (UNILA) e do Programa de Mestrado em Integração Contemporânea da América Latina (PPGICAL). http://orcid.org/0000-0001-7370-3186. Email: fabio.borges@unila.edu.br.

3 Graduado em Relações Internacionais e Integração na Universidade Federal da Integração Latinoamericana (UNILA). Mestrando em Estudos Latino-americanos na Universidade Nacional Autônoma do México (UNAM). http://orcid.org/0000-0001-8865-6773. E-mail: felipenagual@gmail.com.

4 Graduanda em Relações Internacionais e Integração na Universidade Federal da Integração Latinoamericana (UNILA). http://orcid.org/0000-0002-3919-2607. E-mail: luizammart@gmail.com.

REALIS | Digital Object Identifier (DOI): 10.51359/2179-7501.2021.252152 
Abstract: The New Development Bank (NDB) seeks for finance infrastructure and sustainable development projects in the BRICS (Brazil, Russia, India, China and South Africa), and in other emerging economies. Established in 2014, it started operations in 2016. The choice of Shanghai headquarters and the appointment of Chen Yuan, former president of the Chinese Development Bank, to lead the country in the construction of the NDB design, are relevant indicators of the importance that the Chinese government gives to the bank. It was up to Brazil to appoint the president of the NDB in 2020: Marcos Troyjo. Nonetheless, relations between Brazil and China deteriorated in the Bolsonaro period and with the Covid explosion in 2020, when disagreements between these countries reached unprecedented levels. This article will seek to identify the role of China in the NDB and point out contradictions during Brazilian presidency of the bank in a context of global Chinese leadership.

Keywords: China; Protagonism; NDB; Brazil, Contradictions.

\section{Introdução}

O Novo Banco de Desenvolvimento (NBD) é um banco que busca financiar projetos de infraestrutura e desenvolvimento sustentável nos BRICS (Brasil, Rússia, Índia, China e África do Sul), em economias emergentes e países em desenvolvimento. A idealização de um possível banco de desenvolvimento Sul-Sul foi aventada no encontro do G20 em 2011, sendo constituído em 2014 na cúpula dos BRICS em Fortaleza e com início das operações em 2016.

O que torna o NBD relevante e singular no cenário financeiro internacional é a cooperação horizontal entre os membros fundadores do banco: há paridade de votos entre esses, que têm assegurado 55\% do poder de voto conjuntamente. 0 banco não é restrito aos 5 países, permitindo a entrada de qualquer país-membro da $0 \mathrm{NU}$, desde que não tenham mais do que $7 \%$ de poder de voto cada e com a impossibilidade de países desenvolvidos tomarem empréstimos.

É notável o protagonismo chinês no Sistema Internacional atualmente. Angélica Haffner et al. (2015: 7-8) afirmam que nos últimos anos, a China marcou sua participação em todas as arenas internacionais, o que indica que pretende participar da reorganização do poder mundial. Eles argumentam que o governo chinês está usando seu poderio econômico para interferir no tecido financeiro global. Nesse sentido, os mesmos autores (2015: 8) argumentam que, em 2014, a China propôs a criação do Banco Asiático de Investimento em Infraestrutura (AIIB), que, junto ao Banco Asiático 


\section{O protagonismo da China no Novo Banco de Desenvolvimento (NBD)}

de Desenvolvimento, constituíram importantes fontes de financiamento para as economias regionais.

No mesmo sentido, Ramos et al. (2018: 12) argumentam que, curiosamente, a ascensão de Trump nos EUA e sua mudança para o protecionismo econômico relativo colocou a China (geralmente entendida como um modelo diferenciado que levou sua economia para fora dos padrões estabelecidos pelo Consenso de Washington) em uma nova posição: hoje é defensora do mercado aberto e da globalização, e é o principal motor da agenda econômica do BRICS com seus desdobramentos institucionais.

A escolha da sede Xangai e a indicação de Chen Yuan, ex-presidente do Banco de Desenvolvimento Chinês, para liderar o país na construção do desenho do NBD, são indicadores relevantes da importância que os chineses conferem ao banco. Por outro lado, se avalia que a China tem uma estratégia gradual de mudança no Sistema Financeiro Internacional que não se opõe ao Banco Mundial ou ao Fundo Monetário Internacional (FMI), mas também passa a apresentar alternativas ao dólar. De encontro, Santos (2016: 26) defende que o NBD e o Acordo Contigente de Reservas (uma espécie de FMI dos BRICS) representam uma alternativa ao Banco Mundial e ao FMI, pois proporcionam aos BRICS a possibilidade de atuar com agilidade e norteado por critérios distintos do polo de poder hegemônico central do G7, que dominou e ainda domina essas instituições. O NBD não reflete o prelúdio para um afastamento de tais instituições, mas representa uma alternativa. Brandão Martins ilustra algumas dessas inovações impulsionadas especialmente pela China:

In the last summit in Xiamen, in September 2017, it was agreed that the BRICS would establish their own local currency bond fund, and there were also proposals for a transnational multilateral payments system. China, for example, is already working on its own version of a payment system - China Union Pay - to rival Visa and MasterCard, and the CrossBorder Interbank Payment System to rival the predominant SWIFT. This points to a crucial difference between China and Brazil in their engagement in the international financial and monetary system. While China is committed to the creation and innovation of institutions of global financial governance, Brazil though engaged with the BRICS initiatives, does not have a plan as clear as China's about the position it desires to occupy in international financial governance (Brandão Martins, 2018: 48-50).

Caso o NBD seja administrado de maneira igualitária entre seus membros, pautado por princípios técnicos, que sejam ao mesmo tempo claros e diferentes dos que orientam o FMI e o Banco Mundial, e respeitando a soberania dos países receptores de 
empréstimos, essa trajetória de mudança da ordem internacional pode ser aprofundada, dado o potencial que a nova instituição tem para servir de exemplo para mudanças em outros organismos internacionais (Haffner et al.,2015: 13).

Coube ao Brasil indicar o segundo presidente do NDB em 2020 e o escolhido foi Marcos Prado Troyjo. Como ex-vice-ministro da economia do governo Bolsonaro, é interessante tentar projetar o rumo do NBD sob sua direção. De certa forma, sua escolha se contrasta com o padrão da maioria de seus pares no governo Bolsonaro, pois Troyjo possui a formação acadêmica e técnica necessária para ocupar tal cargo no banco. Diplomata de carreira, foi diretor do BRICLab da Universidade de Columbia em 2011, e articulador do Acordo entre Mercosul e União Europeia.

Mas as relações entre e Brasil e China se deterioraram no período Bolsonaro e com a explosão da Covid em 2020, os desentendimentos entre os países atingiram patamares inéditos. Por exemplo, Jamil Chade (2020) faz uma interessante reflexão: “a dificuldade do Brasil em obter acesso às vacinas ou insumos para sua produção não é um acidente. Mas resultado de escolhas políticas e estratégicas que, hoje, cobram seu preço. E no caso da pandemia da Covid-19, um preço em forma de vidas". E detalha que por meses, a chefia do Itamaraty atacou a China, insinuou que o governo de Pequim estaria usando a pandemia para ganhar força internacional, criticou seu embaixador em Brasília, denunciou o "comunavírus" e abriu um fosso inédito entre os dois países. Acrescentando ainda que "agora, ao precisar que as autoridades chinesas liberem a exportação de insumos ou a entrega de mais doses da vacina, se encontram diante de uma muralha.".

Esse artigo buscará identificar o protagonismo da China no NDB e apontar contradições de o Brasil exercer a presidência do banco em um contexto de protagonismo mundial chinês.

\section{1- O Protagonismo Chinês no Sistema Internacional e no NBD}

A ascensão da China como uma nova potência global e os seus efeitos na economia, política e questões de segurança internacional estabeleceram um novo momento geopolítico que os analistas definem como o fim do Século Americano e o início do Século do Pacífico, com a Ásia representando o novo centro de gravidade da economia 


\section{O protagonismo da China no Novo Banco de Desenvolvimento (NBD)}

mundial (Moreno, 2015, p.13).

O sistema internacional sofreu profundas transformações com a ascensão econômica e política da China nas últimas décadas. No plano internacional, a China tem obtido cada vez mais poder no âmbito das instituições multilaterais e das negociações bilaterais com outros países em desenvolvimento e desenvolvidos, projetando o seu poder no tabuleiro geoeconômico e geopolítico asiático e mundial (Cintra \& Pinto, 2017:381-382).

Nessa direção, Pautasso (2019:189) afirma:

A liderança chinesa tem impulsionado processos de integração regionais, tanto através de organizações como a Organização da Cooperação de Xangai (OCX), quanto por meio de iniciativas como a Nova Rota da Seda, ao mesmo tempo que propõe o reposicionamento do país no plano global, bem como a redefinição de elementos-chave da ordem internacional.

Nesse contexto geopolítico global, há muito debate sobre as assimetrias entre os países do BRICS, especialmente o peso e os interesses da China no grupo. Também é analisado se o NBD seria diferenciado das agências de Bretton Woods (FMI e BM) e seria representado como uma alternativa às mesmas.

Nas opiniões de Ramos et al. (2018, p.10), é interessante notar que, de Ekaterinburg a Xiamen, houve progresso institucional em um diálogo constante (e não contra) as instituições internacionais existentes. Segundo os mesmos autores: "In political terms, the BRICS agenda is not one of confrontation, but rather of claiming 'a place at the table' with the Western powers, to gain a bigger voice and greater participation within existing institutions" (Ramos et al., 2018, p. 10-11).

Nesse sentido, o grupo BRICS tentou mostrar que existe uma contradição entre seu potencial econômico e seu papel político. Sobre a relação entre o BRICS e a ordem mundial, os últimos autores argumentam que "por um lado, há uma agenda reformista no BRICS, uma crítica à ordem mundial atual e os ajustes feitos desde o final da Segunda Guerra Fria, por outro lado, é essencial perceber que esses países estão integrados à ordem mundial e seu processo 'emergente' está intimamente ligado aos processos neoliberais da globalização nos últimos vinte anos" (idem). Concluem com a importante consideração:

Although new multilateral arrangements are closely linked to a broader 
Chinese infrastructure finance strategy, as well as to a current critique of the structure of the Bretton Woods institutions (the IMF and the World Bank), they themselves do not openly present themselves as a counterhegemonic alternative. The CRA is particularly interesting on this point. In Article 5 of the Treaty on the Establishment of the Contingent Reserves Arrangement of the BRICS, which deals with the access of the parties to the resources of the CRA, it is stated that access to $70 \%$ of the maximum available for each part depends necessarily on the existence of an ongoing agreement between the IMF and the Requesting Party that involves the IMF's commitment to provide funding to the Requesting Party on a conditional basis and compliance by the Requesting Party with the terms and conditions agreement. That is, the legitimacy of the IMF has been reaffirmed since the very creation of the CRA; in fact, at Xiamen summit there was an agreement "to promote closer cooperation between the IMF and the CRA. (Ramos et al., 2018, p. 11).

Segundo Brandão Martins (2018, p.45), o objetivo do NDB é ser complementar ao papel do Banco Mundial, emitindo empréstimos para promover investimentos para o sustento do desenvolvimento econômico nos BRICS e em outros países em desenvolvimento. O NDB concentra-se em investimentos em infraestrutura e tecnologias verdes e aponta as diferenças importantes com o BM e o FMI:

Unlike the IMF and the World Bank, both institutions claim to impose no conditionalities in the sense of policy recommendations in exchange for credit access. This is an important difference in relation to the traditional institutions. For developing countries, in general, this represents an improvement and considerably reduces the costs of obtaining credit. This lack of standards for credit access is criticized by the developed countries that claim that it could become a means for non-democratic governments to obtain credit without fearing sanctions (Martins, 2018, p. 45-47).

De acordo com Angélica Haffner et al. (2015, p.7-8), nos últimos anos, a China marcou sua participação em todas as arenas internacionais, indicando que pretende participar da reorganização do Sistema Internacional. Argumentam que o governo chinês está usando sua força econômica para interferir na estrutura financeira global. Um fato importante é o papel que tem desempenhado como financiador de infraestrutura. Apontam para a importância do Banco de Desenvolvimento da China (CBD), uma instituição criada em 1994, cuja principal função é fornecer financiamento de médio e longo prazo. O banco foi transformado nos últimos quinze anos e essa mudança estaria ligada às ações de Chen Yuan, que atuou como diretor executivo da CBD de 1998 a 2008, quando se tornou presidente do banco. Sua administração teria mudado a orientação inicial em direção a um banco mais orientado para o desempenho global, com rápida expansão, estimulando os investimentos chineses no exterior. 


\section{O protagonismo da China no Novo Banco de Desenvolvimento (NBD)}

Angélica Haffner et al. fazem uma pergunta central quando questionam que se NBD seria dominado pela China e ditado por seus interesses? Respondem da seguinte maneira:

Essa possibilidade e esse temor são reais, uma vez que o governo de
Pequim desfruta de uma posição privilegiada entre todos os membros
do BRICS. O PIB e o montante de reservas chineses superam com folga o
de todos os outros países combinados. Essa desigualdade vem crescendo
nos últimos anos, com a China sustentando uma taxa de crescimento
bastante superior às do Brasil, Rússia, Índia e África do Sul. Com relação
ao local da sede do banco, os chineses conseguiram fazer com que ele
fosse em Xangai. A cidade não abriga o poder político chinês, o qual está
instalado em Pequim, mas é o centro financeiro do país, a partir de onde
muitas empresas chinesas administram suas operações (Haffner, et al.,
2015, p. 09-10).

Entretanto, Brandão Martins (2018, p.42), efetiva uma interessante ponderação quando argumenta que a China parece ter uma influência maior, pelo menos nas questões econômicas, dentro do grupo. No entanto, o discurso do grupo é que nenhum país lidera apenas o grupo, mas que cada Estado-membro realiza contribuições importantes. É importante ressaltar que essas diferenças tiveram um papel importante na contribuição de cada país do BRICS após a crise financeira de 2008.

Angélica Haffner et al. (2015: 05) apontam que existe o medo de que, no momento em que a China atinja o nível de expansão que deseja, acumule capacidade de influência suficiente para neutralizar o poder dos EUA e possa impor sua agenda internacional, bem como deixar o BRICS. Todavia concluem que:

(...) a China tem motivos para dedicar esforços de sua diplomacia de forma a fazer o grupo BRICS evoluir. Segundo Abdenur (2014), a última e mais importante iniciativa do grupo, o NBD, oferece a oportunidade que a China deseja para apresentar-se ao mundo como uma nação engajada na diplomacia multilateral, uma potência responsável e disposta a negociar com outros países menos desenvolvidos. Apesar de a China já participar de outros organismos financeiros multilaterais, esta é a primeira vez que o país se envolve na concepção e criação de uma instituição desse tipo. Segundo a autora (ibid.), a indicação de Chen Yuan, ex-presidente do Banco de Desenvolvimento Chinês, para liderar uma força tarefa encarregada de participar do desenho do NBD, é um indício do alto nível de importância que os chineses conferem a esta nova instituição (ídem, 2015, p.05).

Angélica Haffner et al. (2015, p.11) apontando mais inovações do NBD argumentam que o financiamento do desenvolvimento do grupo BRICS tem uma filosofia baseada em três pilares. No primeiro, há benefícios mútuos, que implicam ganhos para o país destinatário e o credor, enfatizando a infraestrutura, o investimento e o comércio, 
que expandem a capacidade produtiva - e não apenas apontam para a luta contra a pobreza. 0 segundo é a rejeição da condicionalidade econômica como um mecanismo de concessão de financiamento, visto como uma violação da soberania e da solidariedade. No terceiro, a micro sustentabilidade dos projetos, e não apenas a sustentabilidade da dívida do ponto de vista macroeconômico. Se o NBD mantiver essa filosofia, as possibilidades estratégicas de inserção dos países do Sul serão substancialmente transformadas.

Entretanto, Brandão Martins (2018, p. 47) salienta que o Brasil ocupou a primeira presidência do Conselho de Administração. Devido às instabilidades políticas e econômicas em torno do Brasil, o país não exerceu totalmente sua influência sobre a instituição nos últimos dois anos. Segundo Paulo Nogueira Batista Jr (2017), ex-vicepresidente brasileiro do NBD, o país nunca se representou na reunião de governadores do NBD. Apesar do discurso de que a China não dominará as instituições do BRICS, a realidade é que as contribuições superiores do país, tamanho econômico e robustez podem eventualmente resultar em uma maior influência sobre a dinâmica do Banco.

\section{2- NBD sob presidência brasileira: do protagonismo a defesa do neoliberalismo}

O Brasil teve um papel protagonista na criação do BRICS ainda em suas primeiras reuniões informais em 2006, período correspondente ao governo do ex-presidente Lula e de seu chanceler Celso Amorim. Alguns analistas caracterizavam a política da época como uma política externa ativa, altiva e que defendia a autonomia pela diversificação de sócios estratégicos (Vigevani; Cepaluni, 2007).

Ademais, o economista Paulo Nogueira Batista Junior (2005, p. X) afirmou que a situação do Brasil e da América do Sul evoluiu para melhor, apesar das frustrações com as políticas econômicas e sociais dos dois primeiros anos do governo Lula, "isso porque forças que predominaram na década de 1990 sofreram derrotas em vários países da América do Sul e surgiu um saudável ceticismo em relação a conselhos externos e supostos consensos internacionais". 


\section{O protagonismo da China no Novo Banco de Desenvolvimento (NBD)}

Esse mesmo autor acrescentou que enquanto estancavam as negociações com os países desenvolvidos, avançou gradualmente a integração com a América do Sul e com os países em desenvolvimento de outras regiões e concluiu:

É outra, portanto, a orientação brasileira no campo da política externa e das negociações comerciais. Começamos a superar as posturas atemorizadas, frequentemente subalternas, que marcaram a política internacional do Brasil nos governos Fernando Collor e Fernando Henrique Cardoso (Batista Junior, 2005, p. 12).

Paulo Nogueira Batista Junior por anos foi o representante brasileiro no FMI e teve enorme destaque na criação dos BRICS sendo o primeiro representante brasileiro na instituição. É de se destacar que com as transições de governo no Brasil com o período Temer (2016-2018) e Bolsonaro (2019-atualmente) ele passa a ter problemas em seu relacionamento com o governo brasileiro e por conseguinte também com o banco, sendo afastado em circunstâncias duvidosas. É de se destacar que até hoje esse economista de características heterodoxas faz exposições profundas sobre a história, potencialidades e contradições do NBD .

Como apresentado na introdução, coube ao Brasil indicar o segundo presidente do NBD em 2020 e o escolhido foi Marcos Prado Troyjo. Economista ligado a doutrina neoliberal exerceu o cargo de vice-ministro de Paulo Guedes na Economia e se destacou como articulador do Acordo entre Mercosul e União Europeia. Nesse sentido buscaremos agora avaliar possíveis impactos dessa indicação para o banco e posteriormente possíveis contradições entre os objetivos do NBD e a postura brasileira materializada na representação de Troyjo. Propomos agora analisar um pouco mais sua visão econômica através de algumas obras e declarações.

Em seus livros "Manifesto da Diplomacia Empresarial” (2005) e "Desglobalização: crônicas de um mundo em mudança" (2016) retoma constantemente o conceito de destruição criativa de Joseph Schumpeter, que é a substituição de antigas tecnologias por novas, considerado como o fenômeno essencial do desenvolvimento econômico por essa perspectiva.

Crítico das epistemologias do Sul, Troyjo divide as nações em países tomadores de empréstimos e países comerciantes. Por essa ótica, os primeiros, durante os períodos

5 Um dos eventos mencionados foi "A atuação do BRICS e do NBD: balanço e impactos, com Paulo Nogueira Batista Jr" e que está disponível no link: https://www.youtube.com/watch?v=sZgZeK0wOWA\&t=14s. Acesso em janeiro de 2021. 
de expansão econômica, endividam-se para buscar o desenvolvimento econômico. Porém, para Troyjo o modelo de substituições de importações na América Latina falhou, pois gerou endividamento e não induziu o desenvolvimento tecnológico. Já os países comerciantes, em períodos de bonança tornam-se ainda mais competitivos, aperfeiçoando suas tecnologias e posicionando internacionalmente seus produtos. Em relação aos elementos prebischerianos que Troyjo considera, concorda com a perspectiva que o centro produz destruição criativa em um ritmo mais acelerado que a periferia. Como possível solução, retorna à Schumpeter afirmando que a articulação do desenvolvimento nacional parte das elites, induzida pelo Estado. Cabe às empresas os investimentos e desenvolvimentos tecnológicos para que a destruição criativa da periferia se aproxime do centro. É representativo sobre sua visão de mundo o trecho a seguir:

Diante de tal quadro, a sociedade - e o Estado - não podem perder tempo com atividades de menor relevância. Liberdade é também saber o que privilegiar dentre as tentações do "microgestão" de problemas que podem, e devem, ser resolvidos na própria esfera individual ou concentrar-se nos grandes temas em que o Estado pode desempenhar papel indutor (Troyjo, 2016).

De certa forma, isso estaria alinhado ao que ficou conhecido como regionalismo aberto proposto pela CEPAL nos anos 1990, mas que causou polêmicas devido a sua aproximação do chamado "Consenso de Washington", que pregava as reformas neoliberais. Um dos pontos mais contraditórios é que enquanto a visão original estruturalista da CEPAL (posteriormente dos teóricos da dependência também) via a entrada do capital estrangeiro com preocupação devido à vulnerabilidade externa e dificuldade em se criar um núcleo endógeno de desenvolvimento, a perspectiva neoliberal faz uma grande aposta que o capital estrangeiro daria conta em promover o desenvolvimento econômico e tecnológico das economias periféricas sem a necessidade de um Estado desenvolvimentista. Vale a pena mencionar que essa aposta talvez desconsidere a natureza predominantemente especulativa e financeira da economia mundial atualmente e de seus impactos nas desigualdades e precarização no mundo do trabalho, especialmente em regiões periféricas.

E desenvolve uma classificação muito simplista em três tipos de Estado para defender sua perspectiva sobre seu funcionamento: 


\section{O protagonismo da China no Novo Banco de Desenvolvimento (NBD)}

Estado Babão: aquele que "dorme no ponto", não estabelece regras, nada propõe. Sua inação leva a que, por meio da democracia, antidemocratas crescentemente dilapidem a própria democracia. Estado Ali-Babá: aquele que estabelece uma burocracia hipercodificadora e cleptocrática, cujo principal objetivo é, por meio de obstáculos pseudorregulatórios, rapinar a sociedade de suas riquezas e despojá-la de seu oxigênio de escolha e sua liberdade de criação. Estado Farol: aquele que induz, convida à autorregulação. Sinaliza quais devem ser os interesses nacionais e as ferramentas estratégicas para atingi-los. Permite à sociedade civil plena expressão e o desencadeamento de amplas forças produtivas (Ibidem, p. 2016, p.36).

Troyjo defende o NBD mais como um banco de desenvolvimento do que um órgão dos BRICS. No evento “O NDB e o Brasil: Parceria Estratégica para o Desenvolvimento Sustentável" (2019) se expressou da seguinte forma:

O Novo Banco de Desenvolvimento tem evitado uma série de armadilhas, uma dessas armadilhas era representada pelo Banco tentar fazer uma espécie de foco de oposição a algumas das instituições criadas a partir dos anos 40 a partir da experiência de Bretton Woods. Quem gosta de ver o mundo como confrontacionista pensou a emergência do Banco como algo que se adequaria aquela antiga visão do mundo dividido entre Norte e Sul" (Troyjo, 2019).

E conclui:

Então o NDB tem um papel de ponta de lança nesse mundo, ele é muito mais útil aqui se ele ficar mais perto dessas três palavras Novo Banco de Desenvolvimento, do que apenas banco dos BRICS, ou seja, eu acho que a instituição foi criada também para agregar novos sócios, essa é uma posição brasileira, nós queremos que novos sócios venham se agregar não apenas para ampliar o escopo geográfico, mas também para aumentar as fontes de capitalização (Ibidem, 2019).

E é aí que os aspectos geopolíticos dos BRICS podem colidir com os fundamentos econômicos defendidos por Troyjo. Dentro do cenário conflituoso entre China e Estados Unidos, o distanciamento do NBD dos BRICS é uma possibilidade improvável. 0 protagonismo chinês no NBD contrapõe uma liderança puramente neoliberal no banco. Porém, também há uma convergência entre as prioridades brasileiras e as estratégias chinesas, pois o país tenta impulsionar as privatizações e os chineses encontram ótimas oportunidades de negócios na América do Sul dessa forma.

A última reflexão nesse aspecto é até que ponto uma presidência brasileira no NBD pode impactar a América do Sul. 0 primeiro resultado é que facilite a atração de recursos para o país e região, tanto que se veicula que o Brasil poderá receber até 11 bilhões de dólares em empréstimos do NBD nos próximos anos. Também, o NBD abriu 
uma sede regional em São Paulo, o que pode representar uma maior presença na América do Sul para o banco.

Aparentemente o NBD segue a lógica dos BRICS de defender reformas no sistema internacional para contrabalancear o poder dos EUA, mas ao mesmo tempo não representa uma proposta antissistêmica ao capitalismo ou até mesmo uma contraposição às organizações internacionais já existentes, como Banco Mundial e FMI. Curiosamente, ter um brasileiro com visão neoliberal na presidência do NBD poderá facilitar os negócios da China na América do Sul, mas, ao mesmo tempo, demonstrar que o Brasil perde protagonismo no banco (pois a agenda neoliberal é bastante adaptativa, e pouco propositiva e criativa) e pior ainda, não apresenta mais nenhum tipo de liderança na região sul-americana.

Troyjo (2019) defende o NBD mais como um banco de desenvolvimento do que como um órgão do BRICS. Mantém como "posição brasileira" a possibilidade de agregar novos sócios buscando não só se expandir geograficamente, mas também buscar aumentar as fontes de capitalização. A partir desse entendimento puramente econômico que realiza, pode haver um choque com os aspectos geopolíticos que marcam a formação dos BRICS, especialmente a partir do cenário conflitivo entre China e Estados Unidos. 0 papel da China no NBD contrasta com uma liderança puramente neoliberal no banco. Embora possa haver convergências entre a pretensão brasileira de realizar privatizações e a pretensão chinesa de buscar oportunidades de negócios na América do Sul.

Apesar de o perfil de Troyjo ser moderadamente amenizado em relação à simplificação pró-imperialista do governo brasileiro, sua localização ideológica está plenamente na esfera neoliberal, o que pode trazer contradições com o perfil geopolítico que o BRICS tem desde sua fundação. Somam-se a isso alguns elementos da atual política externa brasileira: sua total subordinação ao governo dos Estados Unidos, sua gestão ambiental desastrosa e as expressões xenófobas de altos funcionários contra a China.

\section{3- Covid em 2020 e o aumento dos desentendimentos entre Brasil e China}

A política externa bolsonarista teve seu mote no discurso da Cerimônia de Posse do Ministro das Relações Exteriores, Ernesto Araújo, em janeiro de 2019. Carregado de referências ao imaginário heleno-clássico, ao neopetencostalismo, a nacionalismos em 


\section{O protagonismo da China no Novo Banco de Desenvolvimento (NBD)}

escritores brasileiros, ao "anti-globalismo" e à paixão pelo nacionalismo estadunidense: "Por isso admiramos os Estados Unidos da América, aqueles que hasteiam sua bandeira e cultuam seus heróis." (Araújo, 2019). Nenhuma menção ao principal parceiro comercial - a República Popular da China - ou aos blocos que participa, como o BRICS, que era central na política externa brasileira durante os governos petistas. 0 Brasil é então colocado como Ocidente, como parte de um só Hemisfério Americano e distante das relações com o Sul Global, como mostra Sawicka (2020) em sua análise sobre a autopercepção brasileira nas relações internacionais na Era Bolsonaro.

O primeiro caso de COVID-19 no Brasil foi reportado em 26 de fevereiro de 2020 (WHO, 2020), cerca de duas semanas após o governo enviar um avião da Força Área para buscar brasileiros em Wuhan, cidade chinesa que foi primeiro epicentro da doença. Durante todo o período que decorreu, os discursos do mandatário brasileiro foi de alinhar a crise sanitária à seguridade econômica - falhando em ambos casos. A projeção de crescimento do PIB brasileiro para 2021 é de -5,8\% (IMF, 2020), e o número de mortos por COVID-19 é o segundo maior do mundo, atrás apenas dos EUA (WHO, 2021).

A crise diplomática com a China na pandemia inicia-se em março de 2020, com publicações no Twitter do presidente da Comissão de Relações Exteriores e de Defesa Nacional da Câmara dos Deputados, Eduardo Bolsonaro (PSL), filho do presidente brasileiro:

Quem assistiu Chernobyl vai entender o q ocorreu. Substitua a usina nuclear pelo coronavírus e a ditadura soviética pela chinesa +1 vez uma ditadura preferiu esconder algo grave a expor tendo desgaste, mas $\mathrm{q}$ salvaria inúmeras vidas A culpa é da China e liberdade seria a solução [sic] (Bolsonaro, 2020)

Em abril, o membro do Alto Escalão do Governo, Ministro da Educação até junho de 2020, Abraham Weintraub, publica na mesma plataforma acusando a China pela pandemia de COVID-19, excluindo a publicação posteriormente: 


\section{(2) Abraham Weintraub o \\ @AbrahamWeint}

Geopolíticamente, quem podeLá

sail foLtalecido, em teLmos

Lelativos, dessa cLise mundial?

PodeLia seL o Cebolinha? Quem

são os aliados no BLasil do

plano infalível do Cebolinha

paLa dominaL o mundo? SeLia o

Cascão ou há mais amiguinhos?

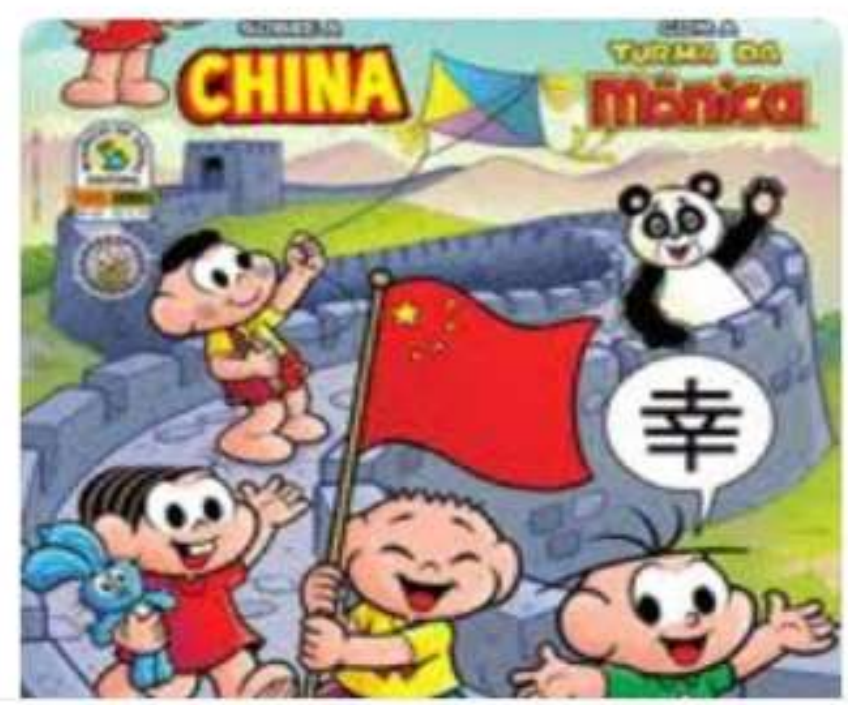

Figura 1 - Publicação de Abraham Weintraub. Fonte: Twitter.

Ernesto Araújo, em seu blog, publica em 22 de abril o texto "Chegou o Comunavírus", fazendo alusão ao regime chinês e à publicação do artigo do filósofo marxista Slavoj Žižek, marcando fortemente a oposição à China, aos mecanismos multilaterais (especialmente a Organização Mundial da Saúde) e ao "globalismo".

Nos casos há a presença do orientalismo e do perigo amarelo (Urbano, 2020), comum em comentários do ex-presidente estadunidense Donald Trump e copiado por membros do governo do Brasil. Entretanto, as relações sino-brasileiras são distintas das sino-estadunidenses, sendo marcada pela dependência causada pela reprimarização latino-americana para atender as demandas chinesas de commodities. Como resposta, a Embaixada da China no Brasil respondeu aos membros do governo em tom firme, sem procedência na história dessas relações, recomendando que o Brasil não se tornasse porta-voz dos EUA, com risco de tropeçar feio. 


\section{O protagonismo da China no Novo Banco de Desenvolvimento (NBD)}

Para Carvalho (2020), a acusação feita pelo deputado Eduardo Bolsonaro “(...) parece ter desconsiderado todos estes elementos e, por isto, foi vista como um ato de hostilidade gratuita contra a China." Como mostra Ibañez (2020), a diplomacia chinesa utiliza a estratégia guerra por outros meios, sem desgastar diretamente as relações adiando acordos, remarcando reuniões ou cedendo interesses às nações que cooperam com sua política.

Com os avanços das pesquisas para a produção da vacina, o laboratório chinês Sinovac Biotech em cooperação com o Instituto Butantã de São Paulo produziu a CoronaVac, aprovada pela Anvisa em 17 de janeiro de 2021. O Ministério da Saúde realizou negociações com o governo de São Paulo, responsável pelo Instituto Butantã, em outubro de 2020 para compra de 46 milhões de doses - o acordo quase consolidado, foi cancelado pelo presidente; anteriormente no mesmo dia, em sua página na rede social Facebook, responde ao comentário de um apoiador que acusa a China de ser uma ditadura com "NÃO SERÁ COMPRADA [sic]". Em contrapartida ao governo federal, o Estado de São Paulo utiliza a paradiplomacia desde o início da pandemia para cooperar com a China, sendo noticiado pela mídia chinesa como principal ator da cooperação Brasil e China (中国新闻, 2021).

A pena do feio tropeçar, como alertado pela Embaixada de Pequim em Brasília, veio com o atraso na entrega dos insumos para produção da vacina e pela dificuldade na negociação com a Índia para a compra de materiais para fabricação da vacina de Oxford/AstraZeneca produzida em cooperação com a Fundação Oswaldo Cruz (RJ). 0 diálogo para a aquisição dos produtos com os chineses passa a ser com o presidente da Câmara dos Deputados, Rodrigo Maia (DEM), e com o governador de São Paulo, João Dória (PSDB); a imprensa brasileira noticia que não há diálogo com Araújo (Gazeta do Povo, 2021). Já com os indianos, o preço pago pela vacina é duas vezes o valor pago pela União Europeia: os europeus compram a AstraZeneca por 2,16 dólares por dose enquanto o Brasil paga US\$ 5,25 (Chade, 2021). Como mostrado por Fuccille (2020), o executivo federal perde protagonismo para agentes paradiplomáticos (governadores estaduais e membros do Congresso), reduzindo sua governabilidade interna e isolandose diplomaticamente dos seus principais parceiros comerciais. Por ora, as relações comerciais permanecem pragmáticas (Severo \& Feres, 2020), mesmo com as 
consequências de a crise diplomática estarem presentes nas negociações para a compra de vacinas.

Os Cinco Princípios de Coexistência Pacífica continuam norteando a política externa chinesa. 0 que o governo de Jair Bolsonaro revela nessa política é o aspecto da mutualidade desses norteadores, tratando a China de forma racista como mostrado por Urbano (2020) - os chineses, assim como povo algum no mundo, não estão dispostos a aceitar tais injúrias (Silva 2020); não estão mais entre o período da Guerra do Ópio e da Revolução de Mao, o chamado Século das Humilhações. Seguindo essa perspectiva, Ribeiro (2020:639), afirma:

O presidente Xi Jinping anunciou uma guerra patriótica contra o vírus, voltando a força do Estado para o controle e combate ao novo coronavírus, apresentando para o mundo um exemplo de organização interna impressionante. A China quer ocupar um vácuo deixado pela perda de prestígio dos EUA nas relações internacionais, se apresentando como uma alternativa a política estadunidense, ao demonstrar que ainda é necessário um Estado engajado nos interesses públicos da sociedade. A pandemia mundial do novo coronavirus será, na conjuntura atual, o momento decisivo para que a China apresente o seu projeto de liderança mundial.

Assim, a China de hoje possui meios e estratégias bem elaboradas para se relacionar com qualquer nação do mundo, e protagoniza as ações desde blocos menores como o BRICS até organizações mundiais, como a OMS.

\section{Considerações Finais}

O NBD se constitui em uma instituição com grande significado geopolítico no Sistema Internacional, demonstrando que o grupo BRICS que nasceu de forma um pouco casual, tem gerado resultados materiais efetivos. 0 banco se mostra inovador e dinâmico, mas também sofre críticas pela velocidade e execução dos créditos aprovados até o momento.

Com os câmbios políticos internacionais e especialmente no Brasil, assistimos um cenário de protagonismo chinês e de crescente marginalização brasileira. No NBD a relevância chinesa é simbolizada pela sede ser em Xangai e pela indicação de Chen Yuan, 


\section{O protagonismo da China no Novo Banco de Desenvolvimento (NBD)}

ex-presidente do Banco de Desenvolvimento Chinês, para liderar o país na construção do desenho do NBD.

Apesar da oportunidade de o Brasil indicar o presidente do NBD em 2020, a indicação de Marcos Troyjo reflete o flerte do atual governo com o neoliberalismo, mas até foi uma escolha com coerência técnica.

Porém as relações entre e Brasil e China se deterioraram no período Bolsonaro e com a explosão da Covid em 2020, os desentendimentos entre os países atingiram patamares inéditos. A política externa bolsonarista se caracteriza pela falta de bom senso e pragmatismo e o os custos se medem através dos indicadores terríveis de mortos brasileiros na pandemia.

Para piorar a situação o governo brasileiro entrou em inadimplência com o NBD. Divulgado pela imprensa brasileira e internacional, o Estado brasileiro está em débito com o banco devido ao mau remanejamento do Orçamento, que foi votado no final de dezembro de 2020. Os parlamentares teriam sido alertados pelo governo da necessidade do capital para pagamento de diversas instituições internacionais, dentre elas, o NBD. Entretanto, os aliados do governo no parlamento brasileiro ignoraram esse ponto e realizaram o remanejo orçamentário para pautas internas priorizadas pelo governo Bolsonaro. A forma de utilização do orçamento é votada pelo Legislativo, contudo, a responsabilidade pelo débito é de ordem Executiva.

Dentro do ambiente do NBD, as consequências estão esclarecidas no artigo 6, cláusula a:

The voting power of each member shall be equal to the number of its subscribed shares in the capital stock of the Bank. In the event of any member failing to pay any part of the amount due in respect of its obligations in relation to paid-in shares under Article 7 of this Agreement, such member shall be unable, for so long as such failure continues, to exercise that percentage of its voting power which corresponds to the percentage which the amount due but unpaid bears to the total amount of paid-in shares subscribed to by that member in the capital stock of the Bank. (New Development Bank, 2015)

Isto é, o Brasil perde poder de decisão em um dos poucos espaços onde tem altivez, prejudicando a própria ação da presidência do banco. Ao passo o Brasil vai dilapi- 
dando sua reputação e prestigio internacional, o protagonismo chinês dentro do banco e a articulação para cooperação dos RICS se tornam mais intensas - a última Cúpula dos BRICS, em novembro de 2020, mostra um Brasil à parte das cooperações, principalmente sanitárias e científicas. Diante da Covid-19, não é mera coincidência que China, Rússia, Índia e África do Sul desenvolveram vacinas próprias e o Brasil segue por caminhos tortuosos e dramáticos. 


\section{O protagonismo da China no Novo Banco de Desenvolvimento (NBD)}

\section{Referências}

ARAÚJO, E. (2020). Chegou o Comunavírus. [Weblog] Metapolítica 17. https://www.metapoliticabrasil.com/post/chegou-o-comunavírus.

ARRIGHI, G. (2008). Adam Smith em Pequim: origens e fundamentos do século. Boitempo.

BOLSONARO, E. [@BolsonaroSP]. (18 de março de 2020). Quem assistiu Chernobyl vai entender o q ocorreu.Substitua a usina nuclear pelo coronavírus e a ditadura soviética pela chinesa +1 vez uma ditadura preferiu esconder algo grave a expor tendo desgaste,mas $q$ salvaria inúmeras vidas A culpa é da China e liberdade seria a solução [Tweet]. Twitter. https://twitter.com/BolsonaroSP/status/1240286560953815040

BRANDÃO, F. M. (2018). New Institutions on the Block: The BRICS Financial Institutions and the Roles of Brazil and China. Journal of China and International Relations, pp. 36-52.

BRICS RUSSIA 2020 (2020). Live streaming of the XII BRICS Summit.https://eng.bricsrussia2020.ru/video/20201117/1141054/Live-streaming-of-the-XII-BRICS-

Summit.html

CARAM, B. (2021). Maia chama governo de incompetente após acusação de ministério contra Congresso. Em Folha de S. Paulo.

https://www1.folha.uol.com.br/mercado/2021/01/maia-chama-governo-deincompetente-apos-acusacao-de-ministerio-contra-congresso.shtml

CARVALHO, E. M. de (2020). O uso político da pandemia e a crise diplomática com a China. Em Augusto, C. B. \& Santos, R. D. dos, (Org.), Pandemias e pandemônio no Brasil, 36-44. Tirant lo Blanch. http://www.unicap.br/catedradomhelder/wpcontent/uploads/2020/05/Pandemias-e-pandemo\%CC\%82nio-no-Brasil.pdf.

CHADE, J. (2020). Novo instrumento da geopolítica, vacina escancara erros do Itamaraty. Em UOL Notícias. https://noticias.uol.com.br/colunas/jamil-chade/2021/01/20/novoinstrumento-da-geopolitica-vacina-escancara-erros-da-itamaraty.htm

CHADE, J. (2021). Para $1^{a}$ entrega, Brasil paga o dobro dos europeus por vacinas. Em UOL Notícias. https://noticias.uol.com.br/colunas/jamil-chade/2021/01/22/para-1aentrega-brasil-paga-o-dobro-dos-europeus-por-vacinas.htm

CINTRA, M. \& PINTO, E. (2017). China em transformação: transição e estratégias de desenvolvimento. Revista de Economia Política, vol. 37, no 2 (147), pp. 381-400. http://www.scielo.br/pdf/rep/v37n2/1809-4538-rep-37-02-00381.pdf

FERNANDES, A. (2021). Brasil deixa de pagar US\$ 292 milhões para aporte no Banco do Brics. Em Estadão. https://economia.estadao.com.br/noticias/geral,brasil-deixa-depagar-us-292-milhoes-para-aporte-no-banco-do-brics,70003570823

FIGUEIRA, M. S., (2015). O Banco dos BRICS como vetor de mudança paradigmática. $5^{\circ}$ Encontro da Associação Brasileira de Relações Internacionais (ABRI), pp. 01-15. 
FUCCILLE, A. (2020). Brasil, Jair Bolsonaro y el COVID-19. Análisis del Real Instituto Elcano, 50/2020.

http://www.realinstitutoelcano.org/wps/portal/rielcano_es/contenido?WCM_GLOBAL_ CONTEXT=/elcano/elcano_es/zonas_es/ari50-2020-fucille-brasil-jair-bolsonaro-y-elcovid-19.

HAFFNER, J. A, MILAN, M. \& ANTONIO, R. (2015). Banco de desenvolvimiento dos BRICS: Origens e Evolução. $5^{\circ}$ Encontro da Associação Brasileira de Relações Internacionais (ABRI), pp. 01-16.

HALPER, S. (2010). The Beijing Consensus: Legitimizing Authoritarianism in Our Time. Basic Books.

LIMA, W. (2021). China pressiona por demissão de Ernesto Araújo para liberar insumos das vacinas. Em Gazeta do Povo. https://www.gazetadopovo.com.br/republica/chinapressiona-demissao-ernesto-araujo-vacinas-covid/

IBAÑEZ, P. (2020). Geopolítica e diplomacia em tempos de Covid-19: Brasil e China no limiar de um contencioso. Espaço e Economia: Revista Brasileira de Geografia Econômica, 18(2317-7837). https://journals.openedition.org/espacoeconomia/13257.

International Monetary Fund, IMF (2020). Brazil and IMF.

https://www.imf.org/en/Countries/BRA

BATISTA JUNIOR, P. N. (2005) O Brasil e a economia internacional: recuperação e defesa da autonomia nacional. Elsevier.

MINISTÉRIO DAS RELAÇÕES EXTERIORES. (2019). Discurso del ministro Ernesto Araújo durante la ceremonia de transmisión de cargo en el Ministerio de Relaciones Exteriores -

Brasília, 2 de enero de 2019 (Portugués). Governo Federal.

https://www.gov.br/mre/es/centro-de-contenidos/discursos-articulos-yentrevistas/ministro-de-relaciones-exteriores-discursos/discurso-do-ministro-ernestoaraujo-durante-cerimonia-de-posse-no-ministerio-das-relacoes-exteriores-brasilia-2-dejaneiro-de-2020.

MORENO, C. (2015). O Brasil made in China: para pensar as reconfigurações do capitalismo contemporâneo. Fundação Rosa Luxemburgo.

NEW DEVELOPMENT BANK, NDB (2015). Agreement on the New Development Bank. https://www.ndb.int/wp-content/themes/ndb/pdf/Agreement-on-the-NewDevelopment-Bank.pdf

PAUTASSO, D. (2019). Desenvolvimento e Poder Global da China: A Política Made in China 2025. Austral: Revista Brasileira de Estratégia e Relações Internacionais, v.8, n.16, Jul./Dez, p.183-198.

RAMOS, L., GARCIA, A., PAUTASSO, D., \& RODRIGUES, F. (2018). A Decade of Emergence: The BRICS' Institutional Densification Process. Journal of China and International Relations, pp. 01-15. 


\section{O protagonismo da China no Novo Banco de Desenvolvimento (NBD)}

RIBEIRO, F. (2020). Geopolítica do século XXI: a perspectiva chinesa do sistema internacional. Geosul, Florianópolis, v. 35, n. 77, pp. 621-644.

https://periodicos.ufsc.br/index.php/geosul/article/view/75746

SAWICKA, M. (2020). Quemando puentes y defendiendo la fe: la relación turbulenta entre Brasil y China en la era Bolsonaro. Anuario Latinoamericano: Ciencias Políticas y Relaciones Internacionales, 10 (2449-8483), 121-146. https://journals.umcs.pl/al/article/view/11291

SILVA, C. L. B. da, (2020). Mascaramento insincero: a política externa do governo Bolsonaro ou Um passeio pelos bosques do cinismo. Espaço e Economia: Revista Brasileira de Geografia Econômica, 18(2317-7837).

https://journals.openedition.org/espacoeconomia/17612

SEVERO, C. C. W. \& FERES, C. P. da C. (2020). O Brasil e o mundo: impactos do governo Bolsonaro e da Covid-19. Revista Espirales, Edição Especial, 9-23. https://revistas.unila.edu.br/espirales/article/view/2323.

STUENKEL, O. (2013). The financial crisis, contested legitimacy and the genesis of intra BRICs cooperation. Global Governance, v. 19, n. 4, p. 611-630.

TOMAZELLI, I. et al (2020). Governo convence Congresso a votar crédito para não dar calote na ONU. Em Estadão. https://economia.estadao.com.br/noticias/geral,governotenta-convencer-congresso-a-votar-credito-para-nao-dar-calote-na-onu,70003554867.

TROYJO, M. P. (2005). Poder e Prosperidade: Cenário Mundial e Nova Economia. Tese apresentada como requisito para a conclusão do Doutorado em Sociologia, Universidade de São Paulo (USP).

TROYJO, M. P. (2016). Desglobalização: crônica de um mundo em mudança. Agbook.

TROYJO, M. P. (2016). Entrevista ao programa Roda Viva.

TROYJO, M. P. (2019). Seminário: O NDB e o Brasil: Parceria Estratégica para o Desenvolvimento Sustentável. https://anchor.fm/funagbrasil/episodes/O-NDB-e-oBrasil--Marcos-Troyjo-e-Andr-Odenbreit-Carvalho-eeo2mr

URBANO et al.. (2020). Orientalismo em tempos de pandemia: discursos sobre a China no jornalismo brasileiro. Rizoma, 8(2318-406X), 106-122.

https://online.unisc.br/seer/index.php/rizoma/article/view/15231

VIGEVANI, T. \& CEPALUNI, G. (2007) A Política Externa de Lula da Silva: A Estratégia da Autonomia pela Diversificação. Contexto Internacional, 29 (2), 273-335.

VISENTINI, P. F. (2011). As Relações diplomática da Ásia: articulações regionais e afirmações mundial (uma perspectiva brasileira). Fino Traço.

SANTOS, C. F. (2016). A Ascensão Pacífica Chinesa e a Participação da China nos BRICS. Revista Ponto de Vista: Perspectivas sobre o Desenvolvimento, v. 2, p. 1-28. 
WORLD HEALTH ORGANIZATION, WHO (2020). Coronavirus disease 2019 (COVID-19) Situation Report - 38. https://www.who.int/docs/defaultsource/coronaviruse/situation-reports/20200227-sitrep-38-covid19.pdf?sfvrsn=2db7a09b_4.

WORLD HEALTH ORGANIZATION, WHO (2021). WHO Coronavirus Disease (COVID-19) Dashboard. https://covid19.who.int/

中国新闻

(2021)。巴西圣保罗州州长高度评价中巴合作。http://www.chinanews.com/gj/2021/ 01-21/9392954.shtml. 